\title{
Current status and future prospects of chemotherapy for metastatic gastric cancer: a review
}

\author{
Atsushi Ohtsu \\ Division of Gastrointestinal Oncology/Digestive Endoscopy, National Cancer Center Hospital East, 6-5-1 Kashiwanoha, Kashiwa 277-8577, \\ Japan
}

\begin{abstract}
Although many randomized trials of chemotherapy for metastatic gastric cancer have been reported during the past two decades, no standard regimens worldwide have been established yet. Reference arms vary depending on the region and cultural differences. To date, a combination of 5-fluorouracil (5-FU) and cisplatin is most widely used. However, no confirmation of survival advantage over single-agent 5-FU in a randomized trial has been proved yet, and there remain limitations of efficacy results in older-generation regimens. Recently developed new agents such as irinotecan, taxanes (paclitaxel and docetaxel), and new oral fluorouracil (S-1 and capecitabine) provided more promising results: a response rate over $50 \%$ and median survival time (MST) over 10 months in their preliminary combination studies. These newer combination regimens are now being investigated in various randomized phase III studies, which will clarify whether the newer-generation regimens provide survival advantage over older-generation regimens. The MST of the new standard should exceed 11 months to be considered a definite improvement, and overall survival seems to be a more desirable primary end point than progression-free survival in a randomized trial. Molecular targeting agents are another concern to improve the treatment outcomes of this disease and are now under investigation in combination with conventional cytotoxic agents. Both clinical and biological research will be more important in future studies.
\end{abstract}

Key words Gastric cancer - Chemotherapy · Treatment · Molecular targeting agent

\section{Introduction}

Unresectable advanced or recurrent gastric cancer still has a poor prognosis, with a median survival of less than 9 months. Randomized trials demonstrated that

Offprint requests to: A. Ohtsu

Received: March 2, 2005 / Accepted: March 5, 2005 5-fluorouracil (5-FU)-based regimens provide superior survival and quality of life in patients with advanced gastric cancer when compared with the best supportive care [1-3]. However, this survival advantage appears to be marginal, and no standard regimens worldwide have been established yet.

Recently developed new agents, such as irinotecan, S-1, capecitabine, docetaxel, paclitaxel, and oxaliplatin may have potentials that will break through this status. Newer-generation regimens with these agents are now being investigated in randomized trials throughout the world. Molecular targeting agents are another new topic in the field of chemotherapy and are also under development for gastric cancer treatment. This review focuses on the results of newer-generation regimens with a brief summary of older-generation regimens.

\section{Overview of the older-generation regimens}

Results from randomized controlled trials (Table 1)

During the past two decades, various randomized trials have been carried out for metastatic gastric cancer. Despite the numerous efforts, there is no accepted global standard regimen at present, and reference regimens differ according to cultural and regional differences. In Europe, a combination of fluorouracil, doxorubicin, and high-dose methotrexate (FAMTX) used to be a standard regimen based on the European Organization for Research and Treatment of Cancer (EORTC) trials [4]. However, this regimen failed to demonstrate any superiority over other combination regimens (5-FU plus cisplatin or etoposide plus 5-FU/ leucovorin) in the subsequent EORTC randomized study [5]. Another randomized study in the United Kingdom revealed superiority of a combination of epirubicin, cisplatin, and 5-FU (ECF) over FAMTX in terms of survival [6], while survival results of these 
Table 1. Results of randomized trials using older-generation regimens

\begin{tabular}{|c|c|c|c|c|c|}
\hline Study (ref \#) & Treatment & $\begin{array}{l}\text { No. of } \\
\text { patients }\end{array}$ & $\begin{array}{l}\text { Response } \\
\text { rate }(\%)\end{array}$ & $\begin{array}{l}\text { Median survival } \\
\text { (months) }\end{array}$ & $P$ value \\
\hline \multirow[t]{2}{*}{ Wils 1991 [4] } & $5 \mathrm{FU}+\mathrm{ADM}+\mathrm{MMC}$ & 103 & 7 & 6.7 & \multirow[t]{2}{*}{0.004} \\
\hline & $5 \mathrm{FU}+\mathrm{ADM}+\mathrm{MTX}$ & 105 & 33 & 9.6 & \\
\hline \multirow[t]{3}{*}{ Kim 1993 [8] } & $5 \mathrm{FU}$ & 94 & 26 & 6.9 & \multirow[t]{3}{*}{ ns } \\
\hline & $5 \mathrm{FU}+\mathrm{ADM}+\mathrm{MMC}$ & 98 & 25 & 6.6 & \\
\hline & $5 \mathrm{FU}+\mathrm{CDDP}$ & 103 & 51 & 8.5 & \\
\hline \multirow[t]{2}{*}{ Webb 1999 [6] } & $5 \mathrm{FU}+\mathrm{ADM}+\mathrm{MTX}$ & 130 & 21 & 5.7 & \multirow[t]{2}{*}{0.0009} \\
\hline & Epirubicin $+\mathrm{CDDP}+5 \mathrm{FU}$ & 126 & 45 & 8.9 & \\
\hline \multirow[t]{3}{*}{ Vanhoefer 2000 [5] } & $5 \mathrm{FU}+\mathrm{CDDP}$ & 134 & 20 & 7.2 & \multirow[t]{3}{*}{ ns } \\
\hline & Etoposide $+\mathrm{LV} / 5 \mathrm{FU}$ & 132 & 9 & 7.2 & \\
\hline & $5 \mathrm{FU}+\mathrm{ADM}+\mathrm{MTX}$ & 133 & 12 & 6.7 & \\
\hline \multirow[t]{3}{*}{ Ohtsu 2003 [9] } & $5 \mathrm{FU}$ & 106 & 11 & 7.1 & \multirow[t]{3}{*}{ ns } \\
\hline & $5 F U+C D D P$ & 104 & 34 & 7.3 & \\
\hline & $\mathrm{UFT}+\mathrm{MMC}$ & 70 & 9 & 6.0 & \\
\hline
\end{tabular}

ns, not significant; 5FU, 5-fluorouracil; ADM, doxorubicin; MMC, mitomycin C; MTX, methotrexate; CDDP, cisplatin; LV, leucovorin; UFT, uracil and tegafur

Table 2. Treatment results of new agents: monotherapy

\begin{tabular}{lccc}
\hline Agent & No. of patients & Response rate & MST (M) \\
\hline CPT-11 & $76(20)$ & $18 \%(25 \%)$ & NS (NS) \\
S-1 & $101(101)$ & $45 \%(45 \%)$ & $8.3(8.3)$ \\
Capecitabine & $44(44)$ & $34 \%(34 \%)$ & $9.5(9.5)$ \\
Docetaxel & $40(40)$ & $18 \%(18 \%)$ & $11.0(11.0)$ \\
Paclitaxel & $60(28)$ & $23 \%(21 \%)$ & $11.5(11.4)$ \\
\hline
\end{tabular}

MST, median survival time; NS, not stated; CPT-11, irinotecan

Parentheses indicate results in the chemonaive patients

studies were limited with a median survival time (MST) ranging from 6 to 8 months and no confirmation of superiority of ECF over two-drug combinations such as cisplatin (CDDP) plus 5-FU (CF). Other trials including using 5-FU alone as a reference arm and comparing it with FU-based combination regimens have been reported from the United States, Korea, and Japan [7-9]. All three trials showed similar results: combination regimens failed to demonstrate survival prolongations as compared with 5-FU alone, while response rates and progression-free survival in the $\mathrm{CF}$ arm were superior to single-agent 5-FU.

Based on the results of these randomized trials, CF could be a reasonable reference arm. However, even this regimen has not shown superiority to 5-FU alone in terms of overall survival, and there still are limitations on efficacy results in older-generation regimens: the response rates ranged from $10 \%$ to $35 \%$, and the MSTs from 6 to 8 months with around $10 \%$ in 2-year survival. To overcome these limitations, new active agents were essential.

\section{Current status of new-generation regimens}

\section{Single-agent studies}

Recently, new-generation agents such as irinotecan, S1, capecitabine, docetaxel, paclitaxel, and oxaliplatin have been developed and investigated for gastric cancer with promising activities [10-15]. Results of single-agent studies are summarized in Table 2. Of the five agents, S-1 achieved the highest response rate, 45\%; and the other agents also showed moderate activity, with response rates of $18 \%$ to $34 \%$. These active agents are now being investigated in combination with other agents.

\section{Combination studies (Tables 3, 4)}

Irinotecan and its combinations

Irinotecan is an inhibitor of DNA-topoisomerase I, which is a crucial enzyme involved in DNA replication and transcription. At first this agent was investigated in combination with CDDP in Japan [16,17]. A phase II study of this combination (irinotecan at $70 \mathrm{mg} / \mathrm{m}^{2}$, day 1 and 15 , and CDDP at $80 \mathrm{mg} / \mathrm{m}^{2}$, day1 every 4 weeks) 
Table 3. Treatment results of newer-generation regimens: two-drug combinations

\begin{tabular}{lccccc}
\hline Regimen & Phase & $n$ & Response rate & MST (M) & Reference (year) \\
\hline Irinotecan+CDDP & II & 29 & $59 \%$ & 10.8 & $17(1999)$ \\
Irinotecan+5-FU/LV & II & 59 & $42 \%$ & 10.7 & $35(2004)$ \\
S-1+CDDP & I/II & 25 & $76 \%$ & 12.5 & $22(2003)$ \\
S-1+irinotecan & I/II & 24 & $50 \%$ & NS & $23(2002)$ \\
Capecitabine+CDDP & II & 42 & $55 \%$ & 10.1 & $27(2002)$ \\
Capecitabine+docetaxel & II & 47 & $40 \%$ & 12 & $28(2004)$ \\
Docetaxel+CDDP & II & 48 & $56 \%$ & 9 & $31(2000)$ \\
Oxaliplatin+5-FU/LV & II & 41 & $43 \%$ & 9.6 & $33(2004)$
\end{tabular}

NS, not stated

Table 4. Treatment results of newer-generation regimens: three-drug combinations

\begin{tabular}{lccccc}
\hline Regimen & Phase & $n$ & Response rate & MST (M) & Reference (year) \\
\hline Paclitaxel+CDDP+5-FU & II & 41 & $55 \%$ & 6 & $30(1999)$ \\
Docetaxel+capecitabine+CDDP & II & 40 & $68 \%$ & 17 & $35(2004)$ \\
Docetaxel+CDDP+5FU & III & 111 & $39 \%$ & 10.2 & $34(2003)$ \\
\hline
\end{tabular}

achieved a high response rate of $48 \%$ with an MST of 9 months in all patients, and of 59\% with an MST of 11 months in chemonaive patients. Toxicities were substantial, the major ones being neutropenia and diarrhea: grade 4 neutropenia was observed in $57 \%$ of patients and grade 3 or 4 diarrhea in $20 \%$. This combination has been modified to a weekly schedule in order to reduce toxicity and has been followed in Western countries. Both of the phase II studies in the United States showed similar activity, with response rates of $58 \%$ and $57 \%$ $[18,19]$. This combination is now being investigated in a randomized phase III trial in Japan.

Another combination was conducted with mitomycin $\mathrm{C}$; the phase I/II study of this combination revealed similar efficacy results and less toxicity than an irinotecan/CDDP regimen [20]. This regimen was then evaluated in the phase II study as a second-line setting after the failure of FU-based regimens [21]. Of the 45 patients registered, 13 achieved partial response, with a response rate of $29 \%$. Median progression-free survival was 4 months. Toxicities were moderate: grade 4 neutropenia was observed in $29 \%$ of patients and grade 3 anorexia in $24 \%$. This study concluded that this regimen could be a treatment option in patients resistant to an FU-based regimen.

\section{Oral fluoropyrimidines and their combinations}

$\mathrm{S}-1$ is a new oral fluoropyrimidine consisting of three components: tegafur, which is a prodrug of 5-FU; 5chloro-2,4-dihydroxypyridine (CDHP), which competes with dihydropyrimidine dehydrogenase; and oxonic acid, which suppresses the gastrointestinal toxicity of tegafur. Various attempts in combination with other agents such as CDDP, irinotecan, and taxanes have been conducted, particularly in Japan. At first, this agent was combined with CDDP. This combination phase I/II study was scheduled as S-1 $40 \mathrm{mg} / \mathrm{m}^{2}$ twice daily for 21 consecutive days and 2-h infusion of CDDP at $60-70 \mathrm{mg} / \mathrm{m}^{2}$ on day 8 , which was repeated every 5 weeks [22]. This study revealed an excellent response rate of $76 \%$ with an MST of 12.6 months. Toxicities were moderate but easily manageable: grade 3 or 4 hematological and nonhematological toxicities were $15.8 \%$ and $26.3 \%$, respectively. Another combination, S-1+CPT-11, is also promising. A phase I/II study of this combination revealed similar response rates of around $50 \%$ with an MST of 14 months [23].

In spite of the promising results in Japan, the development of this agent in Western countries has been interrupted due to severe diarrhea as a side effect. The first European single-agent phase II study had to be decreased from 40 to $35 \mathrm{mg} / \mathrm{m}^{2}$ owing to significant diarrhea [24]. These differences might be caused by higher susceptibility to diarrhea or lower absorption of oxonic acid in Western populations [25]. However, this agent is now being retested using lower doses in the United States. Ajani et al. reported a phase I study of S-1 in combination with CDDP [26]. The predominant doselimiting toxicities were fatigue, diarrhea, and mucositis. Although the maximum tolerated dose of the study (S1 at $25 \mathrm{mg}$ b.i.d for 3 weeks and CDDP at $75 \mathrm{mg} / \mathrm{m}^{2}$ every 4 weeks) was different from that of the Japanese study, the preliminary results were promising and a phase II study is now underway in the United States.

The activity of capecitabine for gastric cancer has also been reported, particularly from Korea. This agent 
Table 5. Ongoing large-scale randomized phase III trials for metastatic gastric cancer

\begin{tabular}{lr} 
Regimen & Target accrual (patients) \\
\hline Western trials & 462 \\
CDDP+5-FU vs. docetaxel+CDDP+5-FU & 337 \\
CDDP+5-FU vs. irinotecan+5-FU/LV & 600 \\
Epirubicin+CDDP+5-FU vs. epirubicin+oxaliplatin+5-FU vs. & \\
Epirubicin+CDDP+capecitabine vs. epirubicin+oxaliplatin+capecitabine & 300 \\
Asian trials & 690 \\
CDDP+5-FU vs. capecitabine+CDDP & 300 \\
Japanese trials & 300 \\
5-FU vs. irinotecan+CDDP vs. S-1 & \\
S-1 vs. S-1+CDDP & \\
S-1 vs. S-1+irinotecan &
\end{tabular}

was first investigated in combination with CDDP (capecitabine at $1250 \mathrm{mg} / \mathrm{m}^{2}$, days $1-14$, and CDDP at $60 \mathrm{mg} / \mathrm{m}^{2}$, day 1 every 3 weeks), showing a response rate of $55 \%$ with an MST of 12 months in a phase II study [27]. Similar promising results were observed with a combination of capecitabine and docetaxel [28]. Kang et al. reported three drug combinations consisting of capecitabine at $1125 \mathrm{mg} / \mathrm{m}^{2}$, days 1-14, docetaxel at $60 \mathrm{mg} / \mathrm{m}^{2}$, day 1 , and CDDP at $60 \mathrm{mg} / \mathrm{m}^{2}$, day 1 , repeated every 3 weeks, which resulted in a high response rate of $68 \%$ (27/40) with a long MST of 17 months [29]. These results warrant further investigations of these capecitabine-based combinations and should be evaluated in large-scale randomized trials.

\section{Taxanes and their combinations}

The taxanes docetaxel and paclitaxel inhibit microtubule depolymerization and have moderate activity against gastric cancer, with a response rate of around $20 \%$ in single-agent studies. Paclitaxel was combined with a CF regimen in the Korean phase II study [30]. Although this three-drug combination achieved a high response rate of $51 \%(21 / 41)$, an MST of 6 months seemed disappointing. The Swiss Group for Clinical Cancer Research has reported a phase II study of docetaxel $85 \mathrm{mg} / \mathrm{m}^{2}$ with CDDP $75 \mathrm{mg} / \mathrm{m}^{2}$ administered once every 3 weeks for advanced gastric cancer, achieving a response rate of $52 \%$, median time to progression of 6.6 months, and an MST of 9 months [31]. This combination was then followed by three-drug combinations adding 5-FU and has been investigated in the randomized trial described later.

\section{Oxaliplatin and its combinations}

Oxaliplatin is an alkylating agent inhibiting DNA replication by forming adducts between two adjacent guanines or guanine and adenine molecules. With the success of the combination of oxaliplatin and 5-FU/ leucovorin $(\mathrm{LV})$ for colorectal cancers, this combination was tested for gastric cancer. Louvet et al. reported a phase II study of oxaliplatin in combination with infusional 5-FU/LV (FOLFOX6) for advanced or metastatic gastric cancer, which resulted in a response rate of $45 \%$ and an MST of 8.6 months [32]. However, FOLFOX6 caused significant toxicity including myelosuppression and peripheral neuropathy. Subsequently the regimen was revised with a reduced dose of oxaliplatin and without bolus infusion of 5-FU. The revised phase II revealed a similar response rate and MST of 9.6 months, with less toxicity than those in the previous study [33]. The authors concluded that the modified FOLFOX6 regimen provided efficacy results comparable with other combination regimens with significantly less toxicity.

\section{Randomized controlled trials including newer-generation regimens}

As mentioned above, various combination regimens including new agents showed promising results in the phase II studies, with response rates of around or above $50 \%$. Most of the new-generation regimens are now being evaluated to determine whether they would provide significant survival prolongations as compared with older-generation regimens (Table 5). Recently, an international randomized controlled trial (V-325) comparing a docetaxel-based regimen with the reference regimen of $\mathrm{CF}$ was reported following an interim analysis [34]. The phase II randomized portion of the study revealed an overall response rate of $28 \%$ with docetaxel/CDDP, and of 43\% with docetaxel/CDDP/5FU (DCF). Subsequently the DCF regimen was chosen as the experimental arm for the phase III stage. The doses and schedule of the DCF arm were: docetaxel $75 \mathrm{mg} / \mathrm{m}^{2}$ on day 1 , CDDP $75 \mathrm{mg} / \mathrm{m}^{2}$ on day 1 , and $5-\mathrm{FU}$ $750 \mathrm{mg} / \mathrm{m}^{2}$ per day as continuous infusion on days $1-5$, repeated every 3 weeks. The dose and schedule of the $\mathrm{CF}$ arm were CDDP $100 \mathrm{mg} / \mathrm{m}^{2}$ day 1 and $5-\mathrm{FU}$ $1000 \mathrm{mg} / \mathrm{m}^{2}$ per day as continuous infusion on days $1-5$, administered every 4 weeks. At the interim analysis on 
232 patients, time to progression was superior $(P=$ 0.0008 ) for DCF (5.2 months vs 3.7 months for CF). The MST was also longer for patients receiving DCF (10.2 months) than for those receiving CF ( 8.5 months). Neutropenic fever, infections, diarrhea, and mucositis were also higher from DCF than from CF. To date, however, the interpretation of the V-325 study results appears to be controversial. Although this study confirmed the superiority of DCF over CF in terms of efficacy, the MST of the DCF arm was 10.2 months, which did not seem a marked improvement. The latest combination studies, as listed in Tables 3 and 4, yielded 12 months or longer MST, although patient numbers were low. Additionally, toxicity of DCF was significant, with grade $3 / 4$ neutropenia of $84 \%$. The decision of whether the superiority of DCF can be accepted should wait until publication of final results. Another international randomized phase II/III study (V306), which compared irinotecan/CDDP with irinotecan plus infusional 5-FU/leucovorin in the phase II portion is now under investigation, mostly in European countries [35]. In that study, $200 \mathrm{mg} / \mathrm{m}^{2}$ of irinotecan and $60 \mathrm{mg} / \mathrm{m}^{2}$ of CDDP were administered every 3 weeks, compared with $80 \mathrm{mg} / \mathrm{m}^{2}$ of irinotecan, $500 \mathrm{mg} / \mathrm{m}^{2}$ of folinic acid (leucovorin, LV), and $2000 \mathrm{mg} /$ $\mathrm{m}^{2}$ of 5-FU as a 24-h infusion per week for 6 weeks followed by 1 week of rest. The overall response rates and MSTs of irinotecan/CDDP and irinotecan/5-FU/LV were $32 \%$ and $42 \%$ and 6.9 and 10.7 months, respectively. Toxicity results also revealed more favorable profiles in irinotecan/5-FU/LV than in irinotecan/ CDDP; therefore, the former regimen has been chosen as the experimental arm for the phase III portion in comparison with the control arm of CF. Superiority of the irinotecan/5-FU/LV has also been observed in a French randomized phase II study comparing 5-FU/LV with $\mathrm{CDDP} / 5-\mathrm{FU} / \mathrm{LV}$ and with irinotecan/5-FU/LV [36]. These two randomized phase II studies suggest that irinotecan/5-FU/LV is the most promising combination regimen; however, confirmation by a phase III study is necessary. In Europe, there is another ongoing study with oxaliplatin used in combination with epirubicin and capecitabine. Patients are randomly assigned to one of the four regimens: ECF (epirubicin/ CDDP/5-FU), EOF (epirubicin/oxaliplatin/5-FU), ECX (epirubicin/CDDP/capecitabine), and EOX (epirubicin/oxaliplatin/capecitabine). The preliminary results available in 2003 showed response rates of $31 \%$, $33 \%, 35 \%$, and $52 \%$ for ECF, EOF, ECX, and EOX, respectively [37]. Complete results will be expected in the near future. The fourth trial is now underway in Asian countries, mostly in Korea, in a study comparing 5-FU/CDDP with capecitabine/CDDP.

In the meantime, many randomized trials consisting of an S-1 based regimen are now being evaluated in Japan. Based on the results of JCOG9205 [9], the JCOG considered single-agent 5-FU as the reference arm and has initiated three-arm randomizations (JCOG9912) comparing 5-FU alone with a combination of irinotecan/CDDP and with $\mathrm{S}-1$ alone. This study requires a sample size of 690 and the accrual will be completed at the end of 2005 . The second study is a postmarketing randomized trial comparing S-1 alone with S-1 + CDDP (sponsored by the Taiho Pharmaceutical Company), with a sample size of 300 . The accrual to this study has been recently completed. The other studies are also designed to have S- 1 as the reference arm: S1 versus 5-FU/LV sponsored by Weiss, and S-1 versus S-1/irinotecan sponsored by the Yakult-Daiichi Pharmaceutical Company.

There may be significant differences between Japan and other countries in interpreting the reference arm. Most countries consider $\mathrm{CF}$, some regions ECF, as the reference arm for metastatic gastric cancer. However, single-agent 5-FU is considered the reference arm in JCOG based on the results of the previous randomized trial (JCOG9205) as well as the Korean and North American trials [7-9], and S-1 monotherapy has been selected as the reference arm in the later trials in Japan. This difference was caused by the different interpretation of the trials comparing single-agent 5-FU with $\mathrm{CF}$, different histories of randomized trials, and cultural differences between the regions. One might say that high response rate and long progression-free survival would provide better quality of life, but another could say that 5-FU alone would provide the same survival as CF, with less toxicity, which seemed to provide better quality of life. In addition, there might be some questions raised: whether combination regimens as front-line therapy have survival advantages over single-agent therapy; determining which is better, simultaneous or sequential combinations; and whether we have to change the primary end point to progression-free survival rather than overall survival. The above ongoing trials will answer these questions, and the MST of the new standard should exceed 11 months to be considered a definite improvement. Contrary to the recent advances in colorectal cancer, no confirmation of improving results with newer-generation regimens as compared with older-generation ones has been achieved yet. It is likely that at first we should confirm definite overall survival prolongation.

\section{Randomized trials in patients with peritoneal metastasis}

The peritoneum is the major site of metastasis from gastric cancer. However, patients with peritoneal metastasis usually are in poor general condition, with impairment of oral intake and complications such as bowel obstruction and hydronephrosis, which may prolong elimination of the agents. Patients with peritoneal dis- 
semination are excluded from a phase II study because these studies usually require response evaluation as a primary end point, whereas these patients usually have no measurable lesions. Thus, a specifically targeted study should be conducted. A phase II study of sequential combination of methotrexate (MTX) plus 5-FU (JCOG9603) has been carried out in patients with malignant ascites [38]. A total of 37 patients were registered; remarkable decreases of ascites were observed in 13 patients (35\%), including $4(11 \%)$ with disappearance of ascites, while $2(5 \%)$ patients died of treatmentrelated toxicity. Based on the results, a phase III study comparing 5-FU alone with MTX/5-FU (JCOG0106) in patients with peritoneal dissemination has been initiated in the JCOG and the accrual will be completed in 2005. Another randomized trial to investigate an efficacy of paclitaxel for this disease is now being conducted as a second-line therapy in JCOG.

\section{Molecular targeting agents under investigation}

Recently developed molecular targeting agents may provide a significant impact in this field, as successful results of bevacizumab and cetuximab have been observed in colorectal cancer $[39,40]$.

Gefitinib is an orally active epidermal growth factor receptor-tyrosine kinase inhibitor that has shown single-agent action against non-small-cell lung cancer. A Japan-Europe joint phase II study was conducted to investigate the efficacy, tolerability, and pharmacokinetics of gefitinib in patients with metastatic gastric adenocarcinoma [41]. Seventy-five patients (32 Japanese, 43 non-Japanese) were randomized to receive $250 \mathrm{mg} /$ day or $500 \mathrm{mg} /$ day gefitinib orally. Disease control was achieved in 13 patients: $1(250 \mathrm{mg} /$ day $)$ had a partial response and $12 \mathrm{had}$ stable disease (4 at $250 \mathrm{mg} /$ day, 8 at $500 \mathrm{mg} /$ day), with a disease control rate of $18 \%$. The most common drug-related adverse events were diarrhea $(45.9 \%)$, rash $(35.1 \%)$, and anorexia (12.2\%). Drug-related grade $3 / 4$ adverse events were experienced by $11.1 \%$ and $23.7 \%$ of patients given $250 \mathrm{mg} /$ day and $500 \mathrm{mg} /$ day gefitinib, respectively. Gefitinib exposure appeared to be unaffected by ethnicity or previous gastric surgery. Furthermore, there was no marked difference in plasma concentration in patients with disease control (partial response plus stable disease) versus progressive disease. In conclusion, gefitinib monotherapy was generally well tolerated but its action seemed to be limited.

Investigations of two other molecular targeting agents are now being planned. EMD72000 is a 95\% humanized monocloncal antibody against EGFR that showed promising activity for colorectal adenocarcinoma in a phase I study [42]. This agent has less toxicity, particularly in allergic reaction and skin rash, than cetuximab, which is a chimeric antibody against EGFR. This agent in combination with a cytotoxic agent will be evaluated in patients with EGFR-positive gastric cancer. Another planned agent is trastuzumab, a monoclonal antibody to Her2 protein, which is widely used in patients with Her2-overexpressing breast cancer. We have evaluated the frequency of Her2 overexpression and the concordance between protein expression and gene amplification in 200 surgical and endoscopic biopsy specimens using two commercial immunohistochemical (IHC) kits (Dako Cytomation, Glostrup, Denmark) and fluorescence in situ hybridization (FISH) (VYSIS, Abbott Laboratories, Downers Grove, IL, USA) [43]. Among these 200 cases, 46 (23\%) of the patients were found to exhibit Her2 protein overexpression. The following IHC scores were obtained: 0: 126 (63\%); 1+: 28 (14\%); 2+: 12 (6\%); and $3+$ : $34(17 \%)$. Gene amplification examined with FISH was observed in 54 cases $(27.1 \%)$. Her2 protein overexpression was observed in $21.5 \%$ of the 200 biopsy specimens $(2+: 7.5 \% ; 3+: 14 \%)$. The concordance rate between the surgically resected materials and the biopsy specimens was $88.7 \%$. From these background results, trastuzumab can be applied for clinical trial in patients with Her 2 overexpressed gastric cancer, and a randomized trial is now being conducted as an international study.

Although the efficacy of the molecular targeting agents is still limited, these agents are the other new hopes for improving efficacy results with less toxicity than conventional cytotoxic agents. Understanding of the biology of gastric cancer may result in better targets or cellular pathways being modified or blocked by therapeutic interventions. Additionally, improvement of the clinical trial design and molecular surrogate into clinical research will lead to the development of better treatments. Both clinical and biological research will be more important.

\section{References}

1. Murad AM, Santiago FF, Petroianu A, Rocha PRS, Rodrigues MAG, Rauch M. Modified therapy with 5-fluorouracil, doxorubicin, and methotrexate in advanced gastric cancer. Cancer 1993; 72:37-41.

2. Glimelius B, Hotfmann K, Haglund U, Nyren O, Sjoden PO. Initial or delayed chemotherapy with best supportive care in advanced gastric cancer. Ann Oncol 1994;5:189-90.

3. Pyrhonen S, Kuitumen T, Nyandoto P. Randomized comparison of fluorouracil, epidoxorubicin and methotrexate (FEMTX) plus best supportive care alone in patients with non-resectable gastric cancer. Br J Cancer 1995;71:587-91.

4. Wils JA, Klein HO, Wagener JT, Bleiberg H, Reis A, Kolsten F, et al. Sequential high-dose methotrexate and fluorouracil combined with doxorubicin - a step ahead in the treatment of advanced gastric cancer: a trial of the European Organization for 
Research and Treatment of Cancer Gastrointestinal Tract Cooperative Group. J Clin Oncol 1991;9:827-31.

5. Vanhoefer U, Rouger P, Wilke H, Ducreux MP, Lacave AJ, Van Cutsem E, et al. Final result of a randomized phase III trial of sequential high-dose methotrexate, fluorouracil, and doxorubicin, versus etoposide, leucovorin, and fluorouracil versus infusional fluorouracil and cisplatin in advanced gastric cancer: a trial of the European Organization for Research and Treatment of Cancer Gastrointestinal Tract Cooperative Group. J Clin Oncol 2000;81: 2648-57.

6. Webb A, Cunningham D, Scarffe H, Harper P, Norman A, Joffe $\mathrm{JK}$, et al. Randomized trial comparing epirubicin, cisplatin and fluorouracil, versus fluorouracil, doxorubicin, and methtrexate in advanced esophagogastric cancer. J Clin Oncol 1997;15:261-7.

7. Cullinan SA, Moertel CG, Wieland HS, O'Connel MJ, Poon MA, Krook JE, et al. Controlled evaluation of three drug combination regimens versus fluorouracil alone for the therapy of advanced gastric cancer. J Clin Oncol 1994;12:412-16.

8. Kim NK, Park YS, Heo DS, Suh C, Kim SY, Park KC, et al. A phase III randomized study of 5-fluorouracil and cisplatin versus 5-fluorouracil, doxorubicin, and mitomycin $\mathrm{C}$ versus 5fluorouracil alone in the treatment of advanced gastric cancer. Cancer 1993;71:3813-18.

9. Ohtsu A, Shimada Y, Shirao K, Boku N, Hyodo I, Saito H, et al. Randomized phase III trial of 5-fluorouracil alone versus 5fluorouracil plus cisplatin versus uracil and tegafur plus mitomycin $\mathrm{C}$ in patients with unresectable advanced gastric cancer: the Japan Clinical Oncology Group Study (JCOG9205). J Clin Oncol 2003;21:54-9.

10. Futatsuki K, Wakui A, Nakano I, Sakata Y, Kambe M, Shimada Y, et al. A late-phase II study of irinotecan hydrochloride (CPT11) in advanced gastric cancer. Gan to Kagaku Ryoho 1994;21: 1033-8.

11. Bang YJ, Kang WK, Kang YY, Kim HC, Jacques C, Zuber E, et al. Docetaxel $75 \mathrm{mg} / \mathrm{m}^{2}$ is active and well tolerated in patients with metastatic or recurrent gastric cancer: a phase II trial. Jpn J Clin Oncol 2002;32:248-54.

12. Yamada Y, Shirao K, Ohtsu A, Boku N, Hyodo I, Saito H, et al. Phase II trial of paclitaxel by three-hour infusion for advanced gastric cancer with short premedication for prophylaxis against paclitaxel-associated hypersensitivity reactions. Ann Oncol 2001; 12:1133-7.

13. Sakata Y, Ohtsu A, Horikoshi N, Sugimachi K, Mitachi Y, Taguchi T. Late-phase II study of novel oral fluoropyrimidine anticancer drug S-1 (1 M tegafur- $0.4 \mathrm{M}$ gimestat $1 \mathrm{M}$ otastat potassium) in advanced gastric cancer patients. Eur J Cancer 1998;34: 1715-20.

14. Koizumi W, Kurihara M, Nakano S, Hasegawa K. Phase II study of S-1, a novel oral derivative of fluorouracil, in advanced gastric cancer. Oncology 2000;58:191-7.

15. Hong YS, Song SY, Lee SI, Chung HC, Choi SH, Noh SH, et al. A phase II trial of capecitabine in previously untreated patients with advanced and/or metastatic gastric cancer. Ann Oncol 2004; 15:1344-7.

16. Shirao K, Shimada Y, Kondo H, Saito D, Yamao T, Ono H, et al. Phase I-II study of irinotecan hydrochloride combined with cisplatin in patients with advanced gastric cancer. J Clin Oncol 1997;15:921-7.

17. Boku N, Ohtsu A, Shimada Y, Shirao K, Seki S, Saito H, et al. Phase II study of a combination of irinotecan and cisplatin against metastatic gastric cancer. J Clin Oncol 1999;17:319-23.

18. Ajani JA, Baker J, Pisters PW, Ho L, Mansfield PF, Feig BW, et al. CPT-11 plus cisplatin in patients with advanced, untreated gastric or gastroesophageal carcinoma. Cancer 2002;94:641-6.

19. Ilson DH, Saltz L, Enzinger P, Huang Y, Kornblith A, Gollub M, et al. Phase II trial of weekly irinotecan plus cisplatin in advanced esophageal cancer. J Clin Oncol 1999;17:3270-5.

20. Yamao T, Shirao K, Matsumura Y, Muro K, Yamada Y, Goto M, et al. Phase I-II study of irinotecan combined with mitomycin $\mathrm{C}$ in patients with advanced gastric cancer. Ann Oncol 2001;12:1729_ 35 .

21. Hamaguchi T, Ohtsu A, Hyodo I, Arai Y, Takiuchi H, Fujii K, et al. A phase II study of irinotecan and mitomycin $\mathrm{C}$ combination therapy in patients with fluoropyrimidine-resistant advanced gastric cancer: The Japan Clinical Oncology Group trial (JCOG0109). Proc Am Soc Clin Oncol 2004;23:Abstr 4071.

22. Koizumi W, Tanabe S, Saigenji K, Ohtsu A, Boku N, Nagashima F, et al. A phase I-II study of S-1 combined with cisplatin in patients with advanced gastric cancer. Br J Cancer 2003;89:220712.

23. Narahara H, Takiuchi H, Tsujinaka T, Furukawa H, Taguchi T. Phase I study of CPT-11 plus S-1 in patients with metastatic gastric cancer. Proc Am Soc Clin Oncol 2002;21:Abstr 677.

24. Chollet P, Shoffski P, Weigang-Kohler K, Schellens JH, Cure H, Pavlidis N, et al. Phase II trial with S-1 in chemotherapy-naive patients with gastric cancer. A trial performed by the EORTC Early Clinical Studies Group (ECSG). Eur J Cancer 2003;39: 1264-70.

25. Peters GJ, Noordhuis P, van Groeningen C, Giaconne G, Holwerda U, Voorn D, et al. The effect of food on the pharamacokinetics of S-1 after single oral administration to patients with solid tumors. Clin Cancer Res 2004;20:4072-6.

26. Ajani JA, Yao J, Faust J, Carr K, Anbe H, Houghton M, et al. Phase I pharmacokinetic study of S-1 plus cisplatin in patients with advanced gastric carcinoma. Proc Am Soc Clin Oncol 2004; 23:Abstr 4043

27. Kim TW, Kang YK, Ahn JH, Chang HM, Yook JH, Oh ST, et al. Phase II study of capecitabine plus cisplatin as first-line chemotherapy in advanced gastric cancer. Ann Oncol 2002;13: 1893-8.

28. Kim HK, Chun JH, Lee JS, Choi JY, Lee GH, Choi IJ, et al. A phase II study of weekly docetaxel and capecitabine in patients with metastatic gastric cancer. Proc Am Soc Clin Oncol 2004;23: Abstr 4057.

29. Kang YK, Kim TW, Chang HM, Ryu MH, Yook JH, Oh ST, et al. A phase I/II trial of docetaxel, capecitabine, and cisplatin as a first line chemotherapy for advanced gastric cancer. Proc Am Soc Clin Oncol 2004;23:Abstr 4064.

30. Kim YH, Shin SW, Kim BS, Kim JH, Kim JG, Mok YJ, et al. Paclitaxel, 5-fluorouracil, and cisplatin combination chemotherapy for the treatment of advanced gastric cancer. Cancer 1999;85;295-301.

31. Roth AD, Maibach R, Martinelli G, Fazio N, Aapro MS, Pagni O, et al. Docetaxel (taxotere)-cisplatin (TC): an effective drug combination in gastric carcinoma. Ann Oncol 2000;11:301-6.

32. Louvet C, Andre T, Tigaud JM, Gamelin E, Douillard JY, Brunet $\mathrm{R}$, et al. Phase II study of oxaliplatin, fluorouracil, and folinic acid in locally advanced or metastatic gastric cancer. J Clin Oncol 2002;20:4543-8.

33. Al-Bartran SE, Atmaca A, Hegewisch-Becker S, Jaeger D, Hahnfeld S, Rummel MJ, et al. Phase II trial of biweekly infusional fluorouracil, folinic acid, and oxaliplatin in patients with advanced gastric cancer. J Clin Oncol 2004;22:658-63.

34. Ajani JA, Van Cutsem E, Moiseyenko V, Tjulandin S, Fodor M, Majilis A, et al. Docetaxel (D) cisplatin, 5-fluorouracil compared to cisplatin (C) and 5-fluorouracil (F) for chemotherapy-naive patients with metastatic or locally recurrent unresectable gastric carcinoma (MGC): interim results of a randomized phase III trial (V325). Proc Am Soc Clin Oncol 2003;22:Abstr 999.

35. Pozzo C, Barone C, Szanto J, Padi E, Peschel C, Bukki J, et al. Irinotecan in combination with 5-fluorouracil and folinic acid or with cisplatin in patients with advanced gastric or esophagealgastric junction adenocarcinoma: results of a randomized phase II study. Ann Oncol 2004;15:1773-81.

36. Bouche O, Raoul JL, Bonnetain F, Giovannini M, Etienne PL, Lledo $\mathrm{G}$, et al. Randomized multicenter phase II trial of a biweekly regimen of fluorouracil and leucovorin (LVFU2), LVFU2 plus cisplatin, or LVFU2 plus irinotecan in patients with previ- 
ously untreated metastatic gastric cancer: a Federation Francophone de Cancerologie Digestive Group Study - FFCD9803. J Clin Oncol 2004;22:4319-28.

37. Sumpter KA, Harper-Wynne C, Cunningham D, Oates J, Tebbut $\mathrm{N}$, Iveson $\mathrm{T}$, et al. Randomized, multicenter phase III study comparing capecitabine with fluorouracil and oxaliplatin with cisplatin in patients with advanced oesophagogastric cancer: confirmation of dose escalation. Proc Am Soc Clin Oncol 2003; 22:Abstr 1031

38. Yamao T, Shimada Y, Shirao K, Ohtsu A, Ikeda N, Hyodo I, et al. A phase II study of sequential methotrexate and 5-fluorouracil for advanced gastric cancer with malignant ascites. Jpn J Clin Oncol 2004;34:316-22.

39. Hurwitz H, Fehrenbacher L, Novotny W, Cartwright T, Hainsworth J, Heim W, et al. Bevacizumab plus irinotecan, fluorouracil, and leucovorin for metastatic colorectal cancer. N Engl J Med 2004;350:2235-42.
40. Cunningham D, Humblet Y, Siena S, Khayat D, Bleiberg H, Santoro A, et al. Cetuximab monotherapy and cetuximab plus irinotecan in irinotecan-refractory metastatic colorectal cancer. $\mathrm{N}$ Engl J Med 2004;351:337-45.

41. Doi T, Koizumi W, Siena S, Castinu S, Ohtsu A, Michael M, et al. Efficacy, tolerability and pharmacokinetics of gefitinib (ZD1839) in pretreated patients with metastatic gastric cancer. Proc Am Soc Clin Oncol 2003;22:Abstr 1036.

42. Vanhoefer, U, Tewes M, Rojo F, Dorsch F, Schleucher N, Rosen $\mathrm{O}$, et al. Phase I study of the humanized antiepidermal growth factor receptor monoclonal antibody EMD72000 in patients with advanced solid tumors that express the epidermal growth factor receptor. J Clin Oncol 2004;22:175-84.

43. Yano T, Ochiai A, Doi T, Hashizume K, Nakanishi H, Ouchi K, et al. Expression of Her2 in gastric cancer: comparison between protein expression and gene amplification using a new commercial kit. Proc Am Soc Clin Oncol 2004;23:Abstr 4053. 